from suffocation. I had previously explained to him the danger of cdema of the lungs, etc., or of the almost positive occurrence of a bronchopneumonia, which, after such harsh experience of the lungs in so extreme a case as this one had been, would be almost certainly fatal, but he still persisted. I had taken several of the members of my laboratory class over with me from the medical college, and thinking that perhaps they might be instructed by witnessing an intubation of the larynx. I consented to put in a tube. The patient was perfectly insensible and limp, and she was held in position for intubation by many hands, but the depression of the lower jaw by means of the gag proved sufficient to obstruct the feeble respirations, and the patient ceased to breathe while I was in the act of intubation. This accident had never happened to me before, and fearing unjust censure I quickly removed the gag, laid the child in a horizontal position, used restoratives and artificial respiration. After prolonged and continuous efforts we succeeded in re-establishing the feeble breathing. I was making preparations to quit the house, being content to leave matters at least no worse than I had found them, when the father again begged as before to do what I could to save his child, so I put the child in position once more and intubated as quickly as I could, and left the thread attached to the tube, and fastened to the ear of the child. She brightened up a little before my departure, and I returned in several hours, found her quite comfortable and breathing naturally. She had, however, bitten the thread in two, and had thrown part of it upon the floor, and had evidently swallowed the other portion, and as there was no unusual irritation in the throat, I did not attempt to ascertain exactly just where the remainder of the string had gone. The case progressed in the usual way, and I removed the tube upon the fifth day, and found several inches of the string still attached to the tube; it had been hanging down in the oesophagus, where it had done no harm. The case continued to progress, and made a perfect recovery.

This is the most extreme case that $I$ have ever had or heard of in which complete recovery occurred, and I think all will agree with me in crediting to Dr. Joseph O'Dwyer's ingenuity the salvation of this case.

I have had somewhat similar cases, but with fatal results, one in which I was called, but found that the patient had actually ceased to breathe. The candles had been lit and the prayers were being said for the dead. I noticed, however, that the platysma myoides had not ceased its spasmodic contractions. Despatching the father hastily to my carriage at the door for my intubation case I hastily intubated. I employed artificial respiration, and succeeded in recalling the almost extinguished respiratory centres, and the little fellow returned to consciousness, and appeared to be out of danger. He partook of nourishment, talked, laughed, and expressed himself as being desirous of going for a drive, etc., but died of pulmonary complications thirty hours afterwards, to the extreme disappointment of his parents, but in strict accordance with my prophecy, which proved alas! too true.

CASE V.-T. B., male, aged 3 years, seen in consultation with Dr. Cook. Had had diphtheritic croup for three days and a half previously; had been in a regular croup-camp, with atomiser, steam, etc., but all the usual urgent symptoms prevailed without abatement. I intubated, and this was followed by marked relief and copious expectoration, and several hours of peaceful sleep. He partook of nourishment well, and on the sixth day, all signs being most favourable, I removed the tube, and pronounced the patient convalescent.

CASE VI.-W. D., male, aged 3 years 3 months, seen in consultation with Dr. Brown. Patient had shown croupy symptoms for several days, and became very markedly croupy. with restlessness, stenosis, and recession. I intubated, and obtained the usual relief. The patient at first swallowed badly, but soon learned to drink in the bent-forward position, and the case proceeded uninterruptedly for five days and a half. Upon removal of the tube by the extractor he, after a few minutes, quieted down, and made a perfect recovery, making a sort of typical case in every particular.

CASR vIr.-F. B., male, aged 5 years 4 months, seen in consultation with Dr. Reynolds. He had previously been under the care of Dr. Dhevlin (uncle to the patient). He had gradually reached a most desperate condition. He was cyanotic, and his countenance expressive of great anxiety. He was restless, and had recession of sternum and marked stenosis. I visited him in the afternoon and advised intubation, but the parents would not consent. About 10 P.M. all symptoms were much more urgent, and the little fellow was dying fast ; then the parents desired that I should intubate. I did so, and he wore the tube for five days. His temperature (104 ${ }^{\circ}$ F.) and pulse (140) were high, and he emaciated rapidly. He was suffering from sepsis. He partook freely of stimulants, quinine, etc.; was treated by corrosive sublimate internally, and locally by atomiser. After removal of thetubehewas very weak; he could not stand alone, and had a catarrhal or septic bronchitis, for which we were obliged to treat him for several weeks with tonics, cod-liver oil emulsions, and wheat phosphates. His convalescence was slow, but he is now in very good condition considering $l$ is recent severe illness.

In the narration of the above cases it will be observed that they were for the most part exceedingly severe in their character, and it would seem like folly even to hope to save them all. In fact, my experience has been more often the other way. Once I was so unfortunate as to lose seven consecutive cases.

The one factor of the greatest success in the remarkable group of cases just related was the comparative slowness, notwithstanding the severe and threatening nature, of the malady. It afforded time in which to do good work. It will be noted that they were not proceeding with that frightful degree of rapidity with which some cases manifest themselves, for within a few days I have been called by two of our most experienced physicians to intubate for croup, and before I could reach them, even when responding within an hour and a half, both cases had terminated fatally.

Intubation is of great assistance in the treatment of diphtheritic croup, but it cannot be expected to eave more than a certain percentage of cases; all that intubation does is to keep the glottis open, 80 that respiration can continue, and it is only an aid in the battle against sepsis, bronchopneumonia, etc. Some cases arefrom the very inception doomed, either from the /rapidity with which they are progressing, or the intensity of the morbid processes at workdying within twenty-four or thirty-six hours, and with the tube perfectly free; while, on the other hand. I have had cases in which it was necessary to keep the tube in the larynx twenty-three days, the stenosis continuing during the whole of that time, and demanding the presence of the tube to prevent suffocation, and yet the patient was finally saved.

The operation of intubation requires from three to eight seconds for its performance; and so accustomed may one become as to be able to intubate without the introducer. On one occasion I had simply a tube with me, and as the case was very urgent, I intubated simply with my hands.

$A$ word as to general results. In 100 consecutive cases of diphtheritic laryngeal croup it has been my good fortune to have saved 38 per cent.

\section{INTUBATION OF THE LARYNX.}

BY G. HUNTKR MACKENZIE, M.D.,

Laryngist to the Eye, Ear, and Throat Infirmary of Edinburgh ; Corresponding Member of the Société de Médecine Pratique de Paris, etc.

THE comparative study of intubation of the larynx on the one hand, and of tracheotomy and laryngotomy on the other, by those who have had experience of these operations, shows that the former has both advantages and disadvantages over the latter. It will probably be found that, especially in young children, the advantages predominate and the results are better.

After intubation in membranous croup (diphtheria of the larynx), I have seen bad results ensue from extension of the membrane beyond the range of the tube-an occurrence which might, of course, also follow tracheotomy. This is indicated by the usual signs of cyanosis, and in addition by a peculiar, laboured "wheezy" expiration of gradual onset. It is of importance to recognise the signs of this extension, as one might otherwise be apt to infer that the tube was at fault, and so have recourse to a fruitless tracheotomy; for intubation does not necessarily preclude a subsequent tracheotomy. Certain disadvantages which appertain more particularly to the operation of intubation are illustrated by the following cases:

1. At the beginning of February of $1889 \mathrm{I}$ intubated, at the request of a practitioner, in the case of a child, aged 21 months. for " membranous croup." The insertion of the tube was followed by marked relief of the breathing, and all went well until about six hours afterwards, when, in my absence, profuse bleeding from the mouth and nose set in. The child died almost immediately. 
Next day I made an examination of the larynx and tube. I found the latter plugged by a clot of blood. There was an erosion of the inferior (posterior) laryngeal artery and vein on the left side, but not sufficient, in my opinion, to account for the bleeding. As permission to make a complete necropsy could not be obtained, I was unable satisfactorily to determine the true source of the hæmorrhage. But this much I could make out, that the tube as it lay in the larynx had nothing to do with its causation.

2. About the middle of the same month I was requested by another practitioner to insert a tube in the case of a child, aged 3 years, who suffered from "croup." The immediate result of the operation was most satisfactory, and nothing could have been better than the ease with which the little patient breathed for about seventy-two hours. On the fourth day, in the absence of the family physician, I was hurriedly sent for, and arrived only to find that the child had died just before I reached the house. On removal and examination of the tube I found it blocked by a firm, dryish, purulent mass, which was with difficulty removed, even after immersion for some time in hot water. Inspection of the larynx was not permitted.

I have been unable to find any record of a case similar to the first, in which the tube was blocked by a clot of blood. The fatal result in the second might, I now think, have been obviated by the removal of the tube on the third day. It had been my intention to do so, but the patient at that time was progressing so satisfactorily that I was induced to let well alone. It is now my rule to remove and examine the tube not later than forty-eight hours after its insertion; should this be followed by laryngeal dyspnœa, reinsertion can easily be effected. I venture to think that in the majority of cases all the benefit that is likely to result will have been accomplis'ed within that period.

3 . In the case of a chil l, aged $4 \frac{1}{2}$ years, I had considerable difficulty in inserting the $t a b e$, and indeed $I$ was not by any mean certain that it was left in its proper position in the larynx. therefore allowed the silk $\rightarrow n$ thread to remain attached, brought it out by the mouth, and fixed it by adhesive plaster round the ear. Several hours before death the child gnawed through the thread, and the tube must then have slipped down the gullet, for on post-mortem examination, I found it lying in the lower section of the cesophagus. A curious point was that the little patient was able to drink without difficulty until a short time before death. On making some experiments with the larynx after death I found it not an easy matter to introduce the appropriate tube, on account of the nariowing of the supraglottic portion of the larynx from membran 9 and infiltration. I would here remark upon the endo-laryngeal distortion which sometimes ensues in diphtheria (membranous croup), and which is best demonstrated by the aid of casts of the larynx. This last case has hitherto been the only one in which I have encountered any real difficulty in inserting the tube.

I have, on a very few occasions, seen the tube expelled by coughing. The probability of this occurrence need not cause alarm, as there is usually ample time for its reinsertion. On one occasion, however, its ejectment was followed by immediate severe dyspnoea. Fortunately, I happened to be in the patient's house at the time, and so was able to replace it at once.

The difficulty in swallowing, which is always present to a greater or less extent so long as the tube is in the larynx, is an an additional reason why the tube should not be left in an hour longer than is absolutely necessary.

I have elected in this short paper to bring forward some of the causes of failure in, and some of the drawbacks to, this operation, believing that a consideration of these will be more useful than an illustrative record of its advantages - of which it is not by any means devoid. After a fair experience of it, I am inclined to think that the operation is one which has made good its claim to a reasonable trial at the hands of the profession. It is doubtless still capable of improvement, especially in the matter of instrumentation

Compared with tracheotomy, I would say that the advantages of intubation of the larynx might thus be summarised : (1) readier consent of relatives, (2) greater ease and rapidity of operation, (3) anæsthetic not necessary, (4) subsequent opening of the windpipe is not precluded. Its disadvantages are connected with (1) deglutition, and (2) blocking, coughing-out, or swallowing of the tube. Also, in cases of laryngeal diphtheria or membranous croup, is may not permit of such free local treatment of the upper air passage, and membrace might be pushed in front of the tube, and so cause occlusion. I think the latter objection more of the nature of a hypothesis than of a well ascertained fact. False membrane in the larynx is usually very closely adherent to the subjacent structures, and its detachment is not so easily accomplished by artificial means as some objectors to intubation would have us believe. I am not conscious of having encountered this mishap.

\section{ON MASSAGE OF THE MEMBRANA TYMPANI AND THE OSSICULA IN THE TREATMENT OF CHRONIC CATARRH OF THE MIDDLE EAR. ${ }^{1}$ \\ BY ADOLF BRONNER, M.D., Surgeon to the Bradford Eye and Ear Hospital.}

THE most common cause of deafness is the so-called "chronic catarrh of the middle ear," or, as some call it, chronic non-suppurative catarrh, or chronic dry catarrh, or sclerosis, or hypertrophic catarrh, or ankylosis of the ossicula, or adhesive catarrh, or the old-fashioned name, chronic obstruction of the Eustachian tube.

No one can accuse the otologists of not having tried all conceivable kinds of remedies for curing this very common affection. They have blown air into the middle ear through the Eustachian tube with Politzer's bag or with the catheter; they have blown all kinds of fumes and vapours into the middle ear; injected many solutions; they have passed bougies, used electrolysis and electricity; they have incised the drumhead, cut through the posterior fold, divided the tensor tympani muscle; they have removed the whole of the drumhead and also the ossicula; they have even opened the mastoid antrum; they have used many local applications to the mastoid process, and given all kinds of medicines.

Professor Lucae, of Berlin, some years ago recommended as a new method that of compressing the air in the external meatus, thus pressing in the drumhead; and of rarefying the air in the external meatus, thus drawing out the drumbead. He, however, soon gave up this method, because, as he said, it gave rise to hyperæmia and inflammation.

Professor Delstanche, of Brussels, has since taken up this idea, and recommends it chiefly in cases of sclerosis or dry catarrh. He has suggested an instrument by which you can alternately compress and evacuate the air in the external meatus, thus moving the drumhead up and down and with it of course the ossicula. In order to avoid the possibility of irritating the drumbead too much, he has attached the apparatus to a Siegle's pneumatic speculum, so that you can, if necessary, carefully control and watch the operation. The apparatus can also be used as a powerful evacuator, in order to break down any adhesions of the drumhead.

Hommel $^{2}$ recommend pressing the tragus into the external meatus with the finger at the rate of 120 times a minute five to six times a day for one to two minutes. Sever l authors, among others Professor Rohrer of Zürich, have carefully tested this method, and without obtaining any good results. In fact, Rohrer tells me that in several cases the hearing became decidedly worse after this process.

In 1884 Professor Lucae ${ }^{3}$ recommended the use of what he calls a "pressure probe" for the treatment of some cases of chronic catarrh of the middle ear. $T /$ is instrument consists of a probe with an enlarged concave end, and attached to a weak spiral spring. The end, covered with cotton-wool or gum, is pressed on to the short process of the malleus, and moved up and down two to ten times, of course under guidance of the frontal mirror. In this manner you move the chain of ossicula, break down any slight adhesions, and loosen the joints of the ossicula. In some cases this is not at all painful, in others, however, very much so. The local application of cocaine does not seem to relieve the pain at all. Lucae only uses the probe in those cases of chronic catarrh in which Rinne's method is negative, and in which "speech" is imperfectly heard. He has only tried it in those cases in which the use of Politzer's method and the Eustachian catheter had failed to improve the hearing. Ont of 44 recorded cases Lucae

$$
1 \text { Read before the Leeds and West Riding Medico-Chirurgical Society. }
$$
2 Archiv fiir Ohrenheillinde, xxiii, 17; "Die mechanische Behandlung des Trommelfeils und der Gehörknöchelchen."

${ }^{3}$ Archiv für Ohrcnhtilkurde, xxi. p. 84, "Über eine methode für mechanis chen Behandlung der chronischen Beweglichkeitsstörungen im schalleitenden Apparat des Gehörgangs." 